\title{
Council Meeting in Bucharest
}

Before the opening of the General Conference in Bucharest the Council of the EPS met to hear of progress made since Amsterdam and to discuss future policy. Professor Casimir presiding over the meeting announced that the Executive Committee had decided formally to appoint Mr. G. Thomas the present Office Manager at Petit-Lancy as Executive Secretary from October 1 , this year.

Opening the reports from the Advisory Committee the Chairman of the Advisory Committee on Applied Physics and Physics in Industry explained that the work of the Committee was largely concerned with advising and collaborating with other bodies to ensure that the needs of applied physicists were taken into consideration when planning conferences, considering publications and so on. At present attention was being given to deepening the collaboration with the Condensed Matter Division and a joint conference was planned to study a particular problem in manufacturing which was amenable to an in-depth scientific investigation. Phosphors was a possible subject.

The Chairman of the Conference Committee reported that the dip in requests for EPS approval indicated in Amsterdam was only temporary and the previous rate of about 40 applications per year was likely to be maintained. A particular problem arose in regard to study conferences and the Committee will in future insist that such conferences do follow the Gordon tradition of being intimate and informal. An investigation was about to be made on how best to administer grants for young participants, and it was necessary to establish soon the policy for the next EPS General Conference to be held in three years time.

The conclusions reached by the Advisory Committee on EPN were summarized to Council. A detailed cost analysis has still to be done but in principle it was agreed that the number of meetings issues should be increased to three per year, one of which will contain EPS directory data and there should be fewer but fatter "green" issues. Members are asked to treat their own copies of EPN as private and to encourage libraries of their institutions to subscribe to EPN especially in view of the increased value of the more frequent and more complete meetings listings. As editorial policy, EPN will pay more attention in the future to science planning questions and physics education in the ordinary numbers.

Council received advance notice of the constitution of the new Advisory Committee on Physics Education which has now been set up under Dr. A. Janner of Nijmegen. One delegate from each of 28 institutions had been invited and over half had agreed actively to participate. Present thinking was to do concentrated work on small problem areas rather than dissipate the effort available over a wider range of subjects.

The Advisory Committee on Publications continues its effective work on controlling and persuading in the publications field. Practically the whole field of physics in Europe has now been covered and the Committee is anxious to receive proposals for deletions, additions, substitutions, etc. in the EPS approved lists. The influence of the work of this Committee has been widely felt in Europe even though its actions rarely make the headlines.

The work of the Divisions of EPS is seen very largely through the conferences they organize or support. A glance at any Meetings Issue will indicate the penetration that EPS has made and the effective collaboration that has resulted from the detailed divisional work. Their activities will as a result not be summarized here.

Consideration was given to the desirability of Summer Schools carrying the EPS badge being located in a single place with which they would become identified and having Study Conferences limited to a small number of locations. It is however too early to name the places.

The proposed changes of the Constitution and By-Laws published in the February issue of EPN were approved by Council. Chairmen of Divisions are now members of Council by right but may not vote on the question of the unit fee as in Council, votes have been carefully balanced between the different categories of members.

The raising of the unit fee was an important item on the agenda of the meeting. Figures produced by the Treasurer showed a healthy trading balance for the past year. The Society made a surplus of $68,000 \mathrm{Fr}$. compared with a loss of $83,000 \mathrm{Fr}$. in 1973 largely due to the drastic cut in the staff; at the same time it made a surplus of $15,000 \mathrm{Fr}$. equivalent in non, convertible currency. Although the Society is now in credit to the value of
48,000 Fr. in non convertible currency its accumulated deficit was otherwise at the end of 1974 some $167,000 \mathrm{Fr}$.

Forecasts indicated that if no measures were taken to counter inflation we should be even worse off in 1979 than now in spite of a temporary improvement in the balance sheet. It was agreed by about 32,000 votes to 2,000 with 1,000 abstentions to raise the unit fee from January 1st 1976 from $6 \mathrm{Fr}$. to $7 \mathrm{Fr}$. although some delegates were obliged to make the reservation that their currency was not convertible.

As a result the EPS can plan its work against a healthy financial background and can expect to be out of the red in $1977 / 78$, able then to consider a modest expansion in its chosen areas of activity.

E.N.S.

\section{A scientific staff position in theoretical physics is available at the Swiss Institute for Nuclear Research (SIN)}

The position entails scientific and administrative chairmanship of the theoretical physics group on a rotational basis. Candidates are expected to carry out independent scientific work in theoretical particle and nuclear physics as well as to participate in other scientific tasks at the institute.

Prerequisites are several years of research experience in nuclear and/or particle physics.

Teaching at the ETH in Zürich is possible and will be encouraged. Applications including curriculum vitae and a list of publications should be mailed to the director of SIN, Prof. J.-P. Blaser, SIN, CH -5234 Villigen, by 31st January 1976.

\section{Editor: L. Sekolec \\ Editorial Board: \\ G.J. Béné, B. GlovanninI, M. Guenin, \\ B. Hauck, S. Newman, E.N. Shaw。 \\ All correspondence to: \\ Editor, EUROPHYSICS NEWS, \\ European Physical Society, \\ P.O. Box 39 , \\ CH - 1213 Petit-Lancy 2 \\ Phone: Geneva 931132 \\ Switzerland.}

Published by the European Physlcal Soclety

Printed by: Ed. Cherlx et Fllanosa SA CH - 1260 Nyon, Switzerland 